\title{
La estructura del Orestes de Eurípides y el enigmático relato del frigio ${ }^{1}$
}

\author{
M. ${ }^{\mathrm{a}}$ Carmen Encinas Reguero \\ Universidad del País Vasco/Euskal Herriko Unibertsitatea \\ mcarmenencinas@gmail.com
}

Recibido: 23 de marzo de 2010

Aceptado: 30 de noviembre de 2010

\section{RESUMEN}

Eurípides divide el Orestes en dos partes separadas por el mechanema, pero lo hace de manera tal que la segunda implica una reinterpretación de la primera. A esta estructura se le superpone una secuencia cronológica inversa, que implica al mismo tiempo una reelaboración también inversa de la Orestea de Esquilo. En dicha reelaboración juega un papel esencial y no siempre bien entendido el relato del frigio. La comparación de esta escena con la protagonizada por Casandra en el Agamenón de Esquilo conduce a una interesante reflexión sobre cuestiones relacionadas con la técnica compositiva.

Palabras clave: Eurípides, Orestes, frigio, Casandra, Esquilo.

\begin{abstract}
Euripides divides Orestes in two parts around the mechanema, in such a way that the second one implies a reinterpretation of the first one. To this structure it is superimposed a chronological inverse sequence, which implies at the same time a reelaboration, also inversed, of Aeschylus' Oresteia. In that reelaboration the scene with the phrygian has a essential and not always understood role. The comparison of this scene with that one, in which Cassandra in Aeschylus' Agammenon plays the leading role, leads to a interesting reflection about matters related to the compositive technique.
\end{abstract}

Key words: Euripides, Orestes, Phrygian, Cassandra, Aeschylus.

${ }^{1}$ Este trabajo ha contado con la financiación del Ministerio de Ciencia e Innovación a través de un proyecto de investigación subvencionado (HUM2006-07163) y mediante el Programa Nacional de Movilidad de Recursos Humanos del Plan nacional de I+D+I 2008-2011. Así mismo, agradezco a la Dra. M. Quijada (Universidad del País Vasco/Euskal Herriko Unibertsitatea) y al Dr. M. Hose (LudwigMaximilians Universität München) la ayuda que me han prestado con la atenta lectura de este trabajo y sus sugerencias al respecto. 
La estructura bipartita del Orestes de Eurípides es un hecho generalmente asumido ${ }^{2}$. A esta estructura bipartita se le superpone un desarrollo lineal inverso, en el que Orestes, como muchas veces se ha dicho ${ }^{3}$, reelabora la temática de la Orestea de Esquilo, pero en sentido opuesto, es decir, desde Euménides hasta Agamenón. En esa reelaboración los personajes euripideos se convierten en cierta medida en dobles, y al mismo tiempo antítesis, de los personajes esquileos. Ése es el contexto en el que Zeitlin propuso interpretar la figura del mensajero frigio como un trasunto de la Casandra de Esquilo 4 . Esa propuesta ha sido ignorada las más de las veces, frontalmente rechazada incluso en alguna ocasión ${ }^{5}$. Sin embargo, defender, si no la identificación entre ambos personajes, sí la utilización consciente por parte de Eurípides en la escena del frigio de algunos recursos formales de la escena de Casandra en Esquilo, conduce, en mi opinión, a cuestiones de interés relacionadas, sobre todo, con la técnica dramática euripidea.

Mi intención en lo que sigue consiste, en primer lugar, en poner de relieve la estructura general del Orestes enfatizando las oposiciones que se establecen entre sus dos partes y, en segundo lugar, en defender la posibilidad de ver en la escena del mensajero frigio un remedo desde el punto de vista técnico de la escena de Casandra en Esquilo, para finalmente ofrecer una interpretación de la repercusión de esa reelaboración en el significado de la tragedia.

\section{ESTRUCTURA DE ORESTES}

El prólogo de Orestes está compuesto por dos escenas. La primera, la rhesis inicial de Electra (vv. 1-70), se centra, sobre todo, en el estado de Orestes tras la acción cometida y la segunda, el diálogo entre Helena y Electra (vv. 71-139), lleva a escena la situación de la mujer de Menelao. Estos dos personajes, Orestes y Helena, viven una situación en cierta medida similar: ambos son rechazados por el pueblo de Argos, que amenaza con lapidarlos (vv. 46-51, 56-60) debido a sus acciones indignas, y por eso permanecen recluidos y se ocultan de las miradas públicas. Ahora bien, a pesar de los rasgos en común, existe una profunda oposición entre ambos ${ }^{6}$, que se manifiesta inicialmente, sobre todo, en los diferentes sentimientos que cada uno suscita en Electra, personaje fundamental en ambas escenas. A través de ella y de sus contrarias

\footnotetext{
${ }^{2}$ Existen autores que proponen otra estructura. Conacher (1967: 213-214), por ejemplo, establece una división de Orestes en tres partes (vv. 1-469, 470-1012 y 1018-final).

${ }^{3}$ Cf., entre otros, Burnett (1971: 205-222), Zeitlin (1980: 55-60), Euben (1986: 233-237), Damen (1990: 139).

${ }^{4}$ Cf. Zeitlin (1980: 59): «There is another important parallel, here an inverted parallel, of the Agamemnon, which has been overlooked, namely, the affinity between the Phrygian slave and Cassandra. The Phrygian slave is himself a polysemous symbol of the play; he is certainly [...] a mirror of Orestes, but surely we can see in him the reverse doublet of the Trojan princess. He babbles in terror in a debased version of Cassandra's mad prophetic ravings as the new representative of Troy in Argos [...]».

${ }^{5}$ Cf. Porter (1994: 174 n. 4): «While the two scenes are alike in their lyrical frenzy, I cannot agree with Zeitlin (1980) 59 that the Phrygian is intended as a perverse inversion of the prophetic Cassandra».

${ }^{6}$ El contraste entre Orestes y Helena es también un contraste entre dos familias, la de Agamenón y la de Menelao, y la distinta fortuna que ha sufrido cada una de ellas.
} 
reacciones ante Orestes y Helena Eurípides pone de relieve la diferencia tan profunda que existe entre esos dos personajes, que se encuentran en una situación semejante. Así, a pesar de su acción matricida, claramente condenada en la obra, Orestes suscita simpatía ${ }^{7}$, mientras que Helena provoca un sentimiento de rechazo y aversión ${ }^{8}$. Pero lo más relevante es que estos dos personajes se encuentran en marcada oposición también en otros niveles.

En primer lugar, Orestes y Helena representan la oposición entre lo masculino y lo femenino, no solo por su propio género, sino también por sus acciones. Orestes es un hombre que ha matado a su madre para vengar a su padre, lo que implica una defensa de la base patriarcal de la sociedad'; Helena, sin embargo, es una mujer (quizás la mujer por excelencia debido a su belleza sin igual), que ha traicionado a Menelao con Paris y ha provocado la muerte de muchos héroes.

En segundo lugar, Orestes y Helena representan también una oposición entre conflicto nacional e internacional o entre política interna y externa, pues, aunque ambos han cometido un crimen contra su familia -Orestes contra su madre, Helena contra su marido- y aunque ambos crímenes han tenido repercusiones públicas, en el caso de Orestes esas repercusiones se han restringido a Argos, mientras que en el caso de Helena se han visto afectadas toda la Hélade y Troya. Pero, además, dado que Argos parece representar la Atenas de la época del autor ${ }^{10}$ y Helena está vinculada con Esparta, la oposición entre Orestes y Helena representa también la oposición entre esas dos ciudades enfrentadas en la guerra del Peloponeso.

Por último, Orestes y Helena representan también en cierta medida una oposición entre el presente ${ }^{11}$ y el pasado ${ }^{12}$, pues mientras la situación del joven es el resultado de una acción reciente, la situación de Helena remite inexorablemente a la guerra de Troya desencadenada tiempo atrás ${ }^{13}$.

${ }^{7}$ Hose (1994: 240) subraya el hecho de que Orestes es la figura que desde el principio queda establecida como canalizadora de la perspectiva del espectador/lector. Mullens (1940: 155) considera que en esta tragedia "Euripides has given the sensible view to an unsympathetic character».

${ }^{8} \mathrm{La}$ Helena del prólogo, que quiere enviar a Electra a realizar ofrendas sobre la tumba de Clitemnestra, recuerda a la Clitemnestra del comienzo de Coéforas de Esquilo, que ha enviado a su hija con ofrendas a la tumba de Agamenón. Sobre esta cuestión, cf. Burnett (1971: 199-201). Por lo general, Helena es considerada un personaje negativo en esta obra, pues negativas son en su mayoría las palabras que los demás personajes pronuncian sobre ella. Sin embargo, Vellacott (1975: 59-63) defiende que este personaje no ha de ser necesariamente valorado de esa manera.

${ }^{9}$ Mullens (1940: 153-154) considera incluso que la misoginia es un rasgo esencial de Orestes en esta tragedia.

${ }^{10}$ La identificación entre Argos y Atenas ha sido asumida por muchos autores. Cf., entre otros, Euben (1986: 222), Hose (1994: 245), Vellacott (1975: 72-73).

${ }^{11}$ Orestes tiene mucho que ver con la situación política real en Atenas a finales del s. V a.C. De hecho, Yates (1995: 193) afirma que "The Orestes in some ways can be read as a Euripidean analogue to the Thucydidean commentary on the history of Athens».

${ }^{12}$ Fuqua (1976: 77) llama la atención sobre el impacto continuo en Orestes del pasado mítico sobre el presente humano, subrayando la importancia de ambos niveles. Zeitlin (1980: 52) considera incluso que «The Orestes is a drama that for all its novelties and innovations is more preoccupied with and more consciously reflective of the past than any other play in the tragic repertory».

${ }^{13}$ Wright (2006) ha interpretado Orestes como una secuela de Helena. Este autor parte del hecho extraño, en su opinión, de que Helena y Menelao tienen un protagonismo en esta obra que sorprende. El 
Pues bien, estos tres pares de oposiciones (masculino-femenino, interno/nacional/ Atenas-externo/internacional/Esparta y presente-pasado) se desarrollan a lo largo de toda la tragedia, con la peculiaridad de que lo masculino, interno/nacional/ateniense y presente predomina en la primera parte, esto es, en la parte que se extiende hasta el planteamiento del mechanema, y lo femenino, externo/internacional/espartano y pasado predomina en la segunda. Y ese movimiento, sobre todo la progresión de lo masculino a lo femenino y de lo presente a lo pasado, se opone, de un lado, a la progresión asumida como lógica y, de otro, a la progresión que se da en la Orestea de Esquilo, la obra a la que Eurípides se refiere indirectamente en Orestes. Si la Orestea comienza con la ejecución del crimen y termina con la discusión y el juicio al respecto, en Orestes se encuentran primero la discusión sobre el matricidio (sobre todo, en la escena con Tindáreo) y el juicio (en la descripción de la asamblea pública) ${ }^{14} \mathrm{y}$ al final la re-ejecución del crimen en la persona de Helena ${ }^{15}$.

El elemento que divide la obra en dos partes es el mechanema o, dicho de otro modo, la elaboración de la intriga (vv. 1098-1245). Hasta llegar al mechanema la obra se desarrolla en gran medida conforme a lo esperado. El mechanema, sin embargo, lo invierte todo ${ }^{16}$. Y así, la segunda parte de la obra reelabora la primera, pero desde otro punto de vista y desde planos opuestos. Esta segunda parte de la tragedia es en gran medida una repetición distorsionada de la primera y al mismo tiempo una reinterpretación de todo lo que esa primera parte implica.

Muchos de los episodios y motivos de la primera parte se encuentran nuevamente en la segunda, aunque transformados ${ }^{17}$. Por ejemplo, la primera palabra de Menelao en la obra se refiere a la casa ( $\tilde{\omega} \delta \tilde{\omega} \mu \alpha$, v. 356), lo que se corresponde con la escena final, en la que Orestes da la orden de quemar el palacio (vv. 1618-1620) ${ }^{18}$. Por otra parte, Tindáreo inculpa a Electra porque «incendió el hogar con un fuego sin llama» (v. 621). Al final Orestes le ordena a Electra quemar el palacio de facto con llamas reales (vv. 1618-1819).

Orestes es, pues, una tragedia compuesta en dos partes divididas por el mechanema, ideado por Pílades ${ }^{19}$ y Electra y aceptado entusiastamente por Orestes ${ }^{20}$. Además, se

motivo es, según él (ibid.: 36), que Eurípides quiere que el receptor de su obra reflexione también sobre estos personajes. En mi opinión, Eurípides utiliza a estos personajes para conducir a una reflexión más amplia sobre la guerra de Troya. Como Euben (1986: 231) explica, «the play not only reduces the heroic ethic to malevolent triviality, it parodies the greatness of the Trojan War».

${ }^{14}$ Tanto la discusión con Tindáreo, como la asamblea argiva llevan el conflicto desde el plano divino, que predomina en Euménides, al plano familiar y político, desacralizando así el tema.

${ }^{15}$ Damen (1990: 139) considera que la inversión en la secuencia cronológica de los hechos es un patrón intencional en todo Orestes. Esta obra avanza hacia atrás en el tiempo, desde la justicia procesal a la recíproca, desde el comportamiento civilizado hasta el barbarismo, invirtiendo el patrón de la Orestea.

${ }^{16}$ Sobre el desarrollo del mechanema en Orestes, cf. Quijada (1991: 217-218).

${ }^{17}$ Scarcella (1956) ha puesto de relieve la presencia de elementos temáticos comunes en las dos partes de la tragedia para refutar las acusaciones de falta de unidad en ocasiones formuladas.

${ }^{18}$ Según Biehl (1968: 220), el incendio del palacio por parte de Orestes significa la extinción de la última huella de una forma de pensar normal.

${ }^{19}$ Sobre la figura de Pílades, cf. Burnett (1971: 213-216).

${ }^{20}$ Orestes, Pílades y Electra son presentados como hetairoi, esto es, miembros de las hetaireiai aristocráticas que proliferaban en la época. Sobre esta cuestión, cf. Hall (1993: 269-270), Hose (1994: 244-245), Hose (2008: 170, 196). 
puede hablar de una composición simétrica, en el sentido de que muchos motivos de la primera parte se corresponden con motivos de la segunda. Esta composición contribuye a la trabazón de la obra.

Pues bien, a esta composición bipartita en torno al mechanema se le superpone una composición lineal inversa, ya que Orestes avanza hacia al pasado y ello, sobre todo, en dos sentidos. De un lado, en sentido cronológico, pues la obra vira hacia el comienzo de la guerra de Troya, que es a la vez el comienzo del conflicto familiar que ha llevado al asesinato de Clitemnestra. De otro lado, en sentido literario, pues la obra se vuelve hacia el inicio de la Orestea, el principal referente literario que subyace bajo Orestes.

Orestes reelabora la Orestea partiendo del juicio, que pone fin a Euménides, hasta llegar al fuego, que, si en Orestes marca al final la destrucción del palacio, anuncia la llegada de Agamenón al comienzo de la trilogía esquilea. Y esto pasando por la súplica a Agamenón (cf. Coéforas $479 \mathrm{ss})^{21}$ y por la escena en la que se oyen, procedentes del interior, los gritos de Helena, mientras Electra incita al asesinato, una escena que reproduce la acción homicida contra Clitemnestra en Coéforas.

Este movimiento inverso desde el punto de vista literario y cronológico, lo es también desde el punto de vista humano, pues en Orestes se da un progreso desde la civilización, reflejada en las discusiones, agones y asambleas políticas de la primera parte de la obra, hacia los instintos y lo irracional, desde la reflexión hacia la pura reacción animal, que se manifiesta en las comparaciones con bestias salvajes ${ }^{22}$, acabando en lo más primigenio, la intervención de la esfera divina.

Al pretender matar a Helena, Orestes intenta repetir el asesinato de Clitemnestra, aunque esta vez sin la orden de Apolo ${ }^{23}$, pero, además, cuando amenaza a Hermíone, la escena recuerda al sacrificio de Ifigenia ${ }^{24}$. Menelao se convierte en un Agamenón que tiene que decidir de nuevo si su hija vive o muere. Aunque algunos críticos consideran que Menelao no tiene intención de ceder y que está dispuesto a dejar que Hermíone sea sacrificada ${ }^{25}$, la mayoría asume que Menelao capitula y decide salvarla. El momento clave al respecto es cuando el Atrida reconoce que Orestes lo tiene en su poder (v. 1617). Al decidir salvar a su hija, Menelao -y, por ende, Eurípides- reescribe el comienzo de la guerra de Troya.

${ }^{21}$ En la medida en que el asesinato de Helena es una reelaboración del de Clitemnestra, se puede afirmar que en Orestes Eurípides reelabora también su Electra. La apelación a Agamenón para que los ayude es una adaptación de la escena correspondiente de Coéforas de Esquilo (vv. 479ss), pero también de la adaptación de esta escena en la Electra de Eurípides (vv. 677ss); cf. Wolff (1983: 340).

${ }^{22}$ En la segunda parte de la obra Orestes, junto con Pílades, es comparado, por ejemplo, con un león

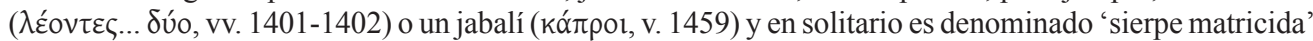

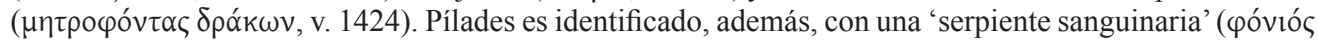
$\tau \varepsilon \delta \rho \alpha ́ k \omega v$, v. 1406).

${ }^{23}$ Cf. Greenberg (1962).

${ }^{24} \mathrm{Cf}$. Euben (1986: 233).

${ }^{25}$ Cf. por ejemplo, Burnett (1971: 193). 


\section{EL ENIGMÁTICO RELATO DEL FRIGIO}

En la reelaboración del pasado que se halla implícita en el Orestes euripideo, donde Menelao es el equivalente de Agamenón, Helena el de Clitemnestra y Hermíone el de Ifigenia, se ha llegado a decir que el frigio representa a Casandra. Esta idea fue avanzada en concreto por Zeitlin ${ }^{26}$, aunque no ha gozado de seguimiento posterior e incluso ha sido explícitamente rechazada en alguna ocasión ${ }^{27}$.

Las similitudes superficiales entre los personajes de Casandra y el frigio son fáciles de percibir. Ambos son dentro de sus respectivos dramas el personaje extranjero llegado de Troya. Además, los dos se expresan inicialmente en versos líricos y su interlocutor es el Coro o Corifeo. La inversión entre ellos (como entre el resto de parejas establecidas ${ }^{28}$ también es evidente. Casandra se dispone a entrar en la casa donde habrá de morir, una acción que acomete con valentía ${ }^{29}$; el frigio sale del palacio en el que ha conseguido escapar de la muerte, dando clara señal de su cobardía. Ella lamenta las desgracias de la casa de Atreo; el frigio lamenta, sobre todo, la destrucción de Troya. El frigio es un hombre con rasgos afeminados; Casandra es una mujer que asume dentro de la tragedia una función que habitualmente les corresponde a personajes masculinos (Tiresias, Heleno) ${ }^{30}$.

Ahora bien, lo importante, yo creo, no es determinar en qué medida el frigio puede representar al personaje de Casandra, pues esto no tiene grandes consecuencias para la interpretación de la tragedia. De hecho, la propia Zeitlin, tras proponer la comparación, no lleva la argumentación mucho más lejos. Lo esencial, en mi opinión, es poner de manifiesto, de un lado, que la función de la profetisa en Esquilo como transmisora de información es, al menos en parte, asumida por el frigio y, de otro, que su escena en conjunto es transformada de un modo muy peculiar dando lugar a un juego literario sutil y sugerente. $\mathrm{Y}$ es esto, que, en definitiva, muestra el modo en que Eurípides utiliza la técnica dramática al final de su carrera, lo que realmente es relevante.

Que Eurípides es un excelente conocedor de la literatura griega, de la tragedia en concreto y particularmente de Esquilo, es un hecho innegable. En Fenicias, por ejemplo, Eurípides lleva a cabo una profunda reelaboración y al mismo tiempo reinterpretación de Siete contra Tebas ${ }^{31}$. Y que en Orestes hace algo similar con la Orestea en el año de su quincuagésimo aniversario parece también fuera de toda duda. Asumir, por tanto, que detrás de la escena peculiar y extraordinaria del frigio pueda subyacer la escena de

\footnotetext{
${ }^{26}$ Cf. nota 4.

${ }^{27}$ Cf. nota 5.

${ }^{28}$ Los personajes de Orestes son un paralelo de los personajes de la Orestea esquilea, pero al mismo tiempo representan una inversión, producto de la reelaboración euripidea: Menelao, como Agamenón, tiene que decidir sobre la vida de su hija, pero él decide salvarla; Helena está a punto de morir a manos de Orestes, como Clitemnestra, pero es salvada por los dioses, mientras que éstos impulsaron a Orestes al matricidio; Hermíone está a punto de ser sacrificada, como Ifigenia, pero finalmente es liberada y entregada en matrimonio.

${ }^{29}$ Sobre el modo en que se expresa la valentía de la acción de Casandra, cf. Iriarte (1996: 79).

${ }^{30}$ Otra gran diferencia entre Casandra y el frigio es que la primera está vinculada a Apolo, mientras que el segundo se relaciona con lo dionisíaco, como Yates (1995: 205-223) ha puesto de relieve.

${ }^{31}$ Cf. Encinas Reguero (2010) (en prensa).
} 
Casandra, central en Agamenón ${ }^{32}$, no parece en principio necesariamente un disparate. Es fundamental, sin embargo, mostrar en qué sentido se puede hablar de reelaboración de esa escena esquilea en la escena del frigio.

Lo primero a considerar es el contenido de ambas escenas. En Agamenón Casandra relata los hechos acontecidos en el pasado en la familia de los Atridas, hechos que ella, como princesa troyana recién llegada de Troya, no ha podido presenciar. Además, anuncia por adelantado también los crímenes que se van a producir en el futuro inmediato dentro del palacio e incluso llega a anticipar la todavía lejana venganza de Orestes. En la obra euripidea el frigio se limita a narrar lo que ya ha sucedido en el interior de la casa real y que él ha presenciado. Se oponen así el conocimiento del pasado y del futuro no presenciados, garantizado por la condición profética de Casandra, y el conocimiento del pasado reciente, garantizado por la condición de testigo presencial del frigio.

Se trata, por lo tanto, de dos tipos distintos de saber y también de dos tipos distintos de narrador. Y, sin embargo, en ambos casos el objeto de la narración son las iniquidades cometidas dentro de la misma familia. Casandra presenció en Troya a través de sus visiones la reducción de la ciudad a cenizas y en la escena de la obra esquilea presencia la destrucción del destructor de su patria, Agamenón. El frigio dice haber visto la caída de Troya y ahora es testigo igualmente del ataque a Helena, la mujer que motivó la guerra.

Pero hay más. En Agamenón Casandra se queja irónicamente de que la persona que podría ayudar en esa situación está lejos (vv. 1103-1104). No está claro a quién se refiere la joven (quizás a Menelao, quizás a Orestes). Si se trata de Menelao, Orestes muestra irónicamente qué clase de ayuda se puede esperar de él. No obstante, la ironía es aún mayor si se entiende que Casandra se refiere a Orestes, porque en ese caso habría que asumir que, frente a Casandra, que ve en Orestes al salvador lejano, el frigio relata en la obra euripidea las acciones del joven, que irónicamente no son salvadoras sino absolutamente destructoras. Si Eurípides, como, de hecho, el escoliasta, entendió que Casandra aludía a Orestes, la escena del frigio, siempre que se acepte la reelaboración esquilea propuesta, gana en significación.

Desde el punto de vista formal, las dos escenas comparten la expresión lírica. Dicha forma es adecuada para la escena de Casandra, pero resulta muy llamativa en la escena del frigio, porque ahí se utiliza para configurar el relato de mensajero, para el que lo característico es el verso recitado. Esto genera una marcada tensión entre la forma (lírica) y el contenido (narrativo) ${ }^{33}$, máxime cuando, además, la forma lírica utilizada en el relato del frigio está absolutamente imbuida de las innovaciones musicales que se desarrollaron en aquellos años de finales del s. V a.C. y que dentro del género trágico afectaban especialmente a la monodia ${ }^{34}$. Encontrar esas innovaciones musicales en un relato de mensajero, que por sus características convencionales sería seguramente el

${ }^{32}$ La escena de Casandra en el Agamenón esquileo es la más larga de la obra y, además, es esencial para entender lo que ha sucedido antes y lo que sucede inmediatamente después. Sobre la escena de Casandra en Agamenón, véase, entre otros, Reinhardt (1949: 97-105), Fraenkel (1964), Knox (1979: $42-$ 55), Whallon (1980: 55-59), McClure (1999: 92-97), Montiglio (2000: 213-216).

${ }^{33}$ Cf. Quijada (2002).

${ }^{34}$ Cf. (ibid.: 90-92). 
elemento trágico en el que la audiencia menos podría esperarlas, causaría, sin duda, cuando menos, sorpresa.

En la escena de Casandra existe una diferencia importante entre el comienzo, en el que la joven se expresa líricamente y donde domina la emoción, y la segunda parte, en la que, al anunciar el relato claro de los hechos, pasa al verso recitado. Es decir, el verso lírico da forma al contenido emotivo y el recitado hace lo propio con el contenido informativo. Eurípides, en cambio, une esos dos elementos contradictorios (forma lírica y contenido narrativo) dando lugar a un relato de mensajero muy peculiar.

La monodia, o mejor, la expresión lírica en general (porque Casandra, aunque se expresa en versos líricos, no pronuncia realmente una monodia; tampoco el frigio en sentido estricto $)^{35}$, tiene unas características particulares en lo que concierne a la relación entre emisor y mensaje. Me refiero al hecho de que la expresión lírica es en gran medida emotiva y da forma a un contenido ya conocido, por lo que no requiere que el emisor justifique su conocimiento de lo que transmite. Casandra tiene un saber excepcional de origen divino y esto le permite, a pesar de proporcionar información novedosa dentro del drama, adoptar una postura omnisciente, que se adapta a la forma lírica. Ahora bien, el relato del mensajero es, dentro de las convenciones trágicas, todo lo contrario. En ningún otro elemento trágico es el establecimiento del conocimiento del narrador tan importante como lo es ahí, en gran medida porque en el relato de mensajero, más que en ningún otro componente de la tragedia griega (con excepción quizás del monólogo del prólogo), se aporta información nueva. Pero, además, en este caso concreto el establecimiento de ese conocimiento es más importante aún, y esto por dos motivos. En primer lugar, porque en el diálogo que precede al relato no se anticipa el contenido fundamental de éste, como es habitual en las escenas de mensajero. En segundo lugar, porque el contenido del relato del frigio no pertenece a la tradición, sino que es innovación de Eurípides ${ }^{36}$. Es decir, tanto la audiencia interna como la externa reciben información nueva en el relato del frigio, de ahí que establecer la fuente de conocimiento de este personaje sea especialmente relevante.

Casandra, como personaje inspirado por Apolo, es capaz de ver el pasado no presenciado y el futuro como si se tratase de algo acontecido ante sus ojos. La capacidad de conocer el futuro es propia de los adivinos y profetas en la literatura griega. La diferencia es que éstos adquieren ese conocimiento generalmente a través de la observación de indicios diversos; Casandra, en cambio, no interpreta indicios, sino que 've' ${ }^{37}$. Por el contrario, el mensajero es, según las convenciones trágicas, un testigo

${ }^{35}$ La escena entre Casandra y el Coro es formalmente un amebeo, en el que inicialmente la parte lírica le corresponde a Casandra y los versos recitados son pronunciados por el Coro. Posteriormente, sin embargo, el Coro estalla también en versos líricos. Al respecto, cf. Fraenkel (1950: 487-488, 538-540). Por su parte, también la escena del frigio es en sentido estricto un amebeo, aunque con partes cantadas de notable entidad. Sobre las dificultades para diferenciar entre el amebeo y la monodia, cf. Barner (1971: 278-279).

${ }^{36}$ Como señala Porter (1994: 188-189), la monodia del frigio es excepcional precisamente porque, al contrario que el resto de monodias, ésta proporciona a la audiencia información nueva. Esa información, además, no solo es nueva para la audiencia interna, sino también para la audiencia externa, porque esos hechos no pertenecen a la tradición, sino que son invención de Eurípides.

${ }^{37}$ Cf. Schein (1982: 11). 
presencial de los hechos que relata. En el caso concreto del frigio, sin embargo, la exposición peculiar de los sucesos parece insinuar la imposibilidad de que él haya sido realmente testigo presencial de todo lo narrado.

Efectivamente, son varios los momentos a lo largo del relato del frigio en los que su autoridad resulta difícil de establecer. Primero el frigio omite cualquier referencia a su persona; después, a instancias del Coro, afirma haber estado junto a Helena mientras sucedían los hechos. Pero si esto es así, no se entiende que sepa lo que sucede con

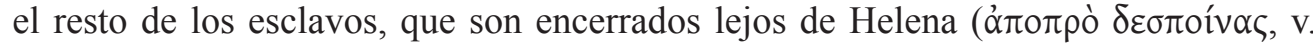
1451). Después, en distintos momentos dice estar con los esclavos o separado de ellos en función de las necesidades de la narración. Es evidente, por lo tanto, que la presentación que hace de los hechos no es completamente realista ${ }^{38}$.

Así pues, tanto Casandra como el frigio se caracterizan, frente al grupo al que pertenecen, por poseer una visión particular. La diferencia es que en el caso de ella, su visión tiene un origen divino (además, los hechos que expone se adaptan al mito) y consecuentemente es una visión autorizada; en el caso del frigio, en cambio, su visión es exclusivamente humana (además, los hechos que narra no pertenecen a ninguna versión conocida del mito) ${ }^{39}$ y el no poder establecer sólidamente su cualidad de testigo presencial socava inexorablemente su autoridad.

El hecho de compartir una forma común (la expresión lírica) explica algunos de los rasgos que la escena de Casandra y la del frigio comparten. Así, por ejemplo, la forma lírica tiende a una expresión más elíptica y, por eso, no sorprende que tanto Casandra como el frigio tiendan a sustituir los nombres de los personajes a los que se refieren por alusiones indirectas, metáforas o perífrasis. Esta forma de expresión es adecuada en la escena de Casandra, pues es propio de este personaje, dada su condición y su vinculación con un saber de origen sobrenatural, expresarse de manera críptica. Ahora bien, el saber del frigio es muy distinto y en su caso la forma lírica y el modo de expresión críptico chocan con las convenciones de la figura del mensajero.

Una de las convenciones más sólidamente establecidas del relato de mensajero es precisamente la apelación de este personaje a su cualidad de testigo presencial de los hechos que narra ${ }^{40}$. Esta apelación es frecuente encontrarla al comienzo del relato de mensajero y el verbo utilizado habitualmente para ello es ópów. El frigio, no obstante, tarda en establecerse como testigo presencial. Indirectamente lo hace, a petición del Coro, al comienzo de la parte segunda de su narración, cuando afirma haber estado junto a Helena (vv. 1426ss). Explícitamente no lo hace, sin embargo, hasta el comienzo de la parte tercera del relato. $Y$ en ese momento el verbo que utiliza

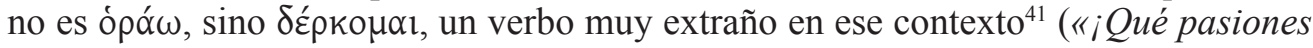

\footnotetext{
${ }^{38}$ Jong (1991: 21-23) percibe también estas contradicciones. En su opinión, Eurípides está jugando con la convención de la presencia invisible y pasiva del mensajero. La violación de la restricción de lugar se utilizar para socavar la claridad del relato.

${ }^{39}$ No es cuestión baladí el hecho de que el frigio narre unos hechos que la audiencia no conocía de antemano por no pertenecer al mito. Este desconocimiento es provocado conscientemente por Eurípides para producir una sensación de desorientación en la audiencia.

${ }^{40}$ Cf. Jong (1991: 9-12).

${ }^{41}$ Jong (1991: 183-184) recoge los verbos con los que se remarca en Eurípides la cualidad de testigo

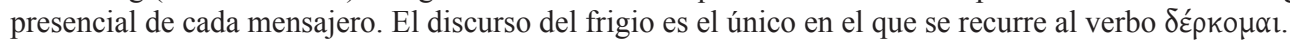




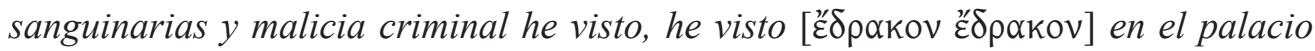
real!», vv. 1455-1457) ${ }^{42}$.

El verbo $\delta \varepsilon ́ \rho \kappa o \mu \alpha l$ es un verbo de 'ver'. El participio $\delta \varepsilon \delta о \rho \kappa \omega ́ \varsigma$, de hecho, se

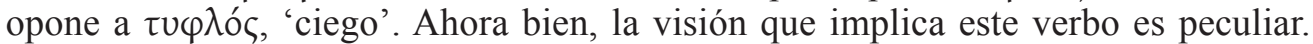

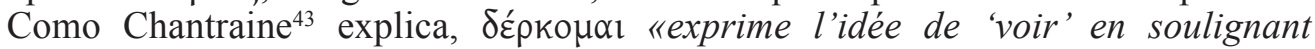
l'intensité ou la qualité du regard [...]. Dit de serpents, de l'aigle, de la Gorgone, de guerriers au combat». En la tragedia griega $\delta \varepsilon ́ p \kappa o \mu \alpha l$ es utilizado con frecuencia en relación con la visión de un dios o de un personaje ligado a la esfera divina, es decir, denotando una visión más allá de lo evidente y cercano. Un buen ejemplo de ello lo proporciona Prometeo en el Prometeo Encadenado de Esquilo («Éstas son señales

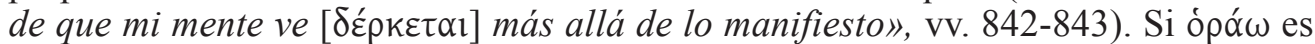
el verbo que utiliza el mensajero trágico habitualmente para subrayar su cualidad de

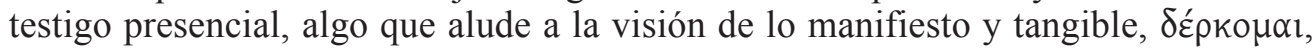
por el contrario, apunta a una visión que va más allá. Como tal, su empleo por parte del frigio es significativo.

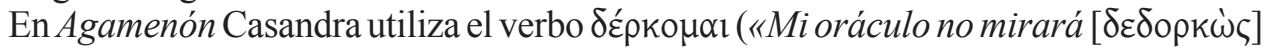
ya detrás de un velo, cual novia recién casada», vv. 1178-1179) $)^{44}$ justo cuando comienza a expresarse en versos recitados y promete un relato claro. La expresión

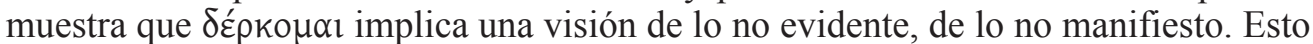
es apropiado en el caso de Casandra, pues su visión es profética. Ella ve sin ver ${ }^{45}$. El frigio, en cambio, por su función de mensajero trágico, ha de ser considerado un simple testigo presencial de los hechos que narra; su visión se ha de entender como la visión de lo que claramente se halla ante sus ojos. El empleo enfático de $\delta \varepsilon ́ p \kappa o \mu \alpha l$ (enfático porque se repite), no obstante, unido al hecho de que la apelación a la visión del frigio en este momento choca con los versos siguientes, en los que dicha visión se cuestiona $^{46}$, parece indicar que el frigio está aludiendo a otro tipo de visión, una visión reservada a quienes están dotados de un saber especial, como es el caso de Casandra.

La autoridad de Casandra emana directamente de la esfera divina (y es socavada igualmente por esa esfera, pues Casandra ha sido castigada por Apolo a no ser creída). En la escena del frigio, la autoridad debería emanar de las convenciones propias de la escena de mensajero. No obstante, éstas chocan con los rasgos impuestos por la forma monódica y con la manipulación consciente de las convenciones por parte del autor

${ }^{42}$ La alusión a la visión de sangre y crímenes dentro del palacio remite de nuevo a Casandra (cf. Agamenón 1090-1092).

${ }^{43}$ Cf. Chantraine (1968: s.v.).

${ }^{44}$ Sobre estos versos, cf. Mitchell-Boyask (2006: 277-278).

${ }^{45}$ Como Iriarte (1996: 69) señala, «además de ser representada en el umbral que separa el mundo de los vivos del de los muertos y en la frontera entre Oriente y Occidente, Casandra se sitúa permanentemente en un espacio indeterminado entre el humano que le es propio y el divino al que le da acceso la inspiración profética. Su existencia se desarrolla alternativamente en los dos niveles dado que ella misma racionaliza los oráculos que ha pronunciado en estado de posesión divina».

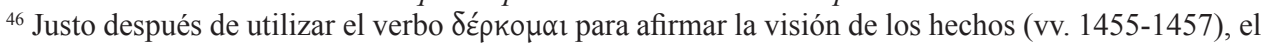
frigio explica que Orestes y Pílades miran a su alrededor para asegurarse de que nadie los ve (vv. 1458bis1459). La contradicción parece clara. 
trágico ${ }^{47} \mathrm{y}$, en consecuencia, la autoridad no logra establecerse sólidamente. De hecho, cuando Menelao entra más adelante en escena y alude a la información recibida, dice no creerla (vv. 1556-1560) y tampoco queda claro qué es lo que el espectador/lector ha de pensar sobre lo sucedido con Helena. Al contrario que los relatos de mensajero al uso, esta narración del frigio no consigue despejar totalmente las dudas respecto a lo acontecido en el interior del palacio.

Así pues, parece claro que la forma y los rasgos de la escena de Casandra son utilizados en la escena del frigio, pero al servicio de un elemento diferente: la narración del mensajero. Eurípides utiliza el modelo esquileo, pero lo distorsiona conscientemente. El siguiente paso, por tanto, es tratar de determinar qué persigue el dramaturgo con ello.

Para empezar, el modo en que Eurípides compone la escena del frigio como una reelaboración de la escena de Casandra afecta a la función de la escena. La escena de Casandra cumple en gran medida con la función de una escena de mensajero, aunque formalmente no lo es. Casandra desvela lo que va a suceder inmediatamente en el palacio y hace que no sea necesario un mensajero para dar cuenta a posteriori de ello. Cuando se escuchan sobre el escenario los gritos del rey, el espectador entiende de inmediato -y el Coro intuye-, gracias a las palabras de Casandra, lo que ha sucedido en el interior del palacio ${ }^{48}$. Es decir, la de Casandra es una escena trenética, que funcionalmente sustituye a la narración. La escena del frigio, por el contrario, es una escena de mensajero, que incluye características formales del threnos. Eurípides toma una escena esquilea y la reelabora creando un elemento técnicamente inverso. No es tanto el contenido lo que Eurípides reproduce y transforma, cuanto los rasgos formales y funcionales. Al hacerlo Eurípides juega con la forma literaria y experimenta, dejando clara su absoluta maestría y dominio técnicos. Pero, además, se muestra como un verdadero crítico literario, que advierte lo esencial de la técnica esquilea y la adapta e invierte en un ejercicio de pura intelectualidad.

En segundo lugar, al utilizar los rasgos propios de la escena de Casandra, Eurípides logra dotar a la escena del frigio de unos efectos similares. Efectivamente, un efecto de la escena de Casandra en Agamenón es que el hecho puntual (el próximo asesinato de Agamenón y el suyo propio) se sitúa dentro de un contexto más amplio. Es decir, al aludir a los hechos pasados (historia de Atreo y Tiestes) y a los del futuro (la venganza de Orestes), se inserta el asesinato de Agamenón dentro de un contexto de causas y efectos mucho más complejo y amplio. Esto es propio de las partes líricas de la tragedia. Por el contrario, el relato de mensajero se limita, según la convención dramática, a narrar los hechos sucedidos en el pasado más reciente. Cuando en la tragedia griega se inserta el relato de hechos lejanos en el tiempo, se hace a través de los personajes

\footnotetext{
${ }^{47}$ Obsérvese que, si en la escena de Casandra es Apolo el que confiere autoridad a la joven y socava al mismo tiempo su credibilidad, en Orestes Eurípides cumple implícitamente una función similar a la del dios, pues él presenta al frigio como un testigo presencial, pero al mismo tiempo manipula las convenciones para privarlo de credibilidad. En Agamenón el Coro se ve abocado a no creer a Casandra; en Orestes es, sobre todo, la audiencia externa la que se enfrenta a la dificultad de poder creer la información que se da en escena.

${ }^{48}$ Reinhardt (1949: 101) señala como una de las funciones de la escena de Casandra, «den zu erwartenden Botenbericht zu erübrigen, so daß zuletzt ein Todesschrei, der aus dem Hause dringt, genügt, um alles klar werden zu lassen».
} 
principales del drama, pero no a través de la figura del mensajero. Pues bien, gracias a la alusión a los hechos de Troya y al paralelismo implícito entre el ataque a Helena y el de Clitemnestra ${ }^{49}$, pero también gracias a la forma lírica y a las características que ésta impone, tomadas, en mi opinión, en cierta medida de la escena de Casandra, Eurípides logra expandir el relato del frigio. Aunque aparentemente éste es tan solo la narración de un suceso concreto acaeido poco antes, los numerosos ecos que se establecen entre esos hechos y otros del pasado, así como el tipo de narración lírica, que implica emoción y atemporalidad, y la ruptura de la autoridad, que deriva de un modo de narración rayano en la omnisciencia, contribuyen a dar profundidad y amplitud al relato, lo que pone de manifiesto una vez más la habilidad dramática de Eurípides.

Por otra parte, al reelaborar la escena de Casandra en la del frigio Eurípides invierte y transforma su recepción y el efecto en la audiencia. Casandra es creída por su interlocutor, el Coro, en lo referente al pasado, pero no en lo que afecta al futuro. El espectador/lector, no obstante, conocedor del mito, lo entiende todo. En la escena del frigio Eurípides desarrolla un tema ajeno al mito, con lo que suprime el conocimiento superior de la audiencia, y al mismo tiempo pone el relato en labios de un narrador, cuya autoridad queda cuestionada y que reconoce no saber lo que ha sucedido con Helena. El Coro, interlocutor interno, no parece dudar de los hechos, aunque sí lo hace Menelao, quien no cree en la explicación aportada por el frigio. El espectador/lector no tiene base firme para saber qué ha sucedido realmente. De hecho, es Apolo, como deus ex machina, el que tiene que dar finalmente esa información (vv. 1633-1634). Así, en cierto modo, el público es conducido en Orestes a una experiencia similar a la del Coro en Agamenón, aunque en relación con el pasado.

Por último, entender la escena del frigio como una reelaboración de la de Casandra implica una secularización significativa. En Agamenón Casandra está dotada de inspiración profética y al mismo tiempo está condenada por Apolo a no ser creída. El carácter divino de la escena es determinante ${ }^{50}$. En Orestes la narración está a cargo de un personaje absolutamente humano ${ }^{51}$, cuya autoridad puede emanar tan solo de las propias convenciones trágicas. Por eso, la ruptura, al menos parcial, de esas convenciones implica también una disminución de su autoridad. Lo divino, por tanto, se seculariza en Orestes $^{52}$.

${ }^{49}$ También gracias al hecho de que, como Porter (1994: 176) apunta, la monodia del frigio describe el ataque a Helena en términos que recuerdan a la Ilíada de Homero.

${ }^{50}$ Como Leahy (1969: 145) señala, «Cassandra is presented here to reveal the theological implications of what has gone before».

${ }^{51}$ El miedo del frigio y su deseo de sobrevivir a toda costa se pueden interpretar como una inversión de los rasgos de Casandra o como una manera de acentuar su carácter antiheroico y cómico, tantas veces puesto de relieve. En cualquier caso, esas características hacen del frigio también un personaje absolutamente humano.

${ }^{52}$ La secularización de lo sagrado se advierte también en la primera parte de la tragedia, donde el juicio con participación divina de Euménides se ha convertido en una asamblea popular argiva estrictamente política. Romilly (1972: 237) advierte ya que la asamblea, innovación de Eurípides, implica en la obra el paso de lo divino a lo humano. 


\section{CONCLUSIÓN}

Eurípides somete el pasado, histórico y cultural, a un profundo cuestionamiento en Orestes. La obra se desarrolla de manera en cierta medida previsible hasta el mechanema, pero cuando parece que los jóvenes no tienen más opción que la muerte, se produce lo insospechado: una idea nueva, contraria a lo esperado y a lo esperable, lo trastoca todo. $\mathrm{Y}$ esa nueva idea conduce a una reinterpretación del pasado en sentido cronológico y literario.

La primera parte de la obra cuestiona la situación presente y el funcionamiento de las instituciones en Atenas; la segunda parte, cuestiona el pasado, pero, sobre todo, cuestiona el pasado más glorioso, el de la guerra de Troya. En Esquilo la escena de Casandra supone un alto en la acción, que insta a la reflexión ${ }^{53}$. A través de esa escena lo que sucede dentro de la casa se hace visible en el escenario y se une, además, a una secuencia más amplia de hechos. Por su parte, la escena del frigio, con las múltiples resonancias logradas a través de la forma lírica, del contenido y de la propia figura del frigio, causa sorpresa y, en consecuencia, provoca también una reflexión más amplia que una escena de mensajero habitual. No se trata ya solo de lo que acaba de suceder en el interior del palacio, sino que esos hechos se vinculan con un todo más amplio y complejo.

Afirmar que el frigio representa en Orestes a la Casandra del Agamenón es quizás un exceso, que no lleva muy lejos, además, en el nivel de la interpretación de la obra, pero cuando se analizan las respectivas escenas protagonizadas por estos personajes, no se puede dejar de percibir una similitud técnica y funcional, que difícilmente puede ser casual y cuyo significado es mucho más revelador.

En el año 408 a.C., cuando Orestes es representada por primera vez, se cumplía el quincuagésimo aniversario de la primera representación de la Orestea, una obra ampliamente conocida y reconocida. Que en el esquema general de Orestes Eurípides sigue en orden inverso el drama esquileo es algo que parece aceptado. En mi opinión, también se ha de aceptar que en la escena del frigio Eurípides reelabora la escena de Casandra.

Eurípides toma una escena trenética de función narrativa y la transforma en una escena narrativa de forma trenética; toma a un personaje excepcional con respecto a su grupo por su visión, Casandra, y lo transforma en un personaje, el frigio, cuya visión se diferencia también de la de sus iguales, los mensajeros trágicos; toma una escena que genera incertidumbre en su interlocutor interno y la transforma en una escena que, en contra de la convención, genera incertidumbre incluso en la audiencia externa.

Sin duda alguna, Eurípides crea en la escena del frigio una escena que sorprende, pero no solo por su forma lírica y sus innovaciones musicales aplicadas a un elemento tradicionalmente narrativo, o porque en ella todo se opone a lo esperado, según las convenciones dramáticas, sino también porque sus rasgos excepcionales tienen su origen en una escena aparentemente muy diferente, la de Casandra. Y a través de la reelaboración de esa escena en Orestes Eurípides se muestra como un crítico literario, que apunta a lo que es excepcional y clave en el viejo modelo esquileo y lo toma y

\footnotetext{
${ }^{53}$ Según Schein (1982: 15), «we learn through Cassandra’s suffering».
} 
lo transforma en algo absolutamente novedoso en un ejercicio de genialidad técnica indiscutible.

Se ha hablado con respecto a los dramas finales de Eurípides de la ruptura de los límites trágicos y, en consecuencia, del fin de la tragedia. Sin duda, el género ha cambiado en el Eurípides más tardío. Sin embargo, aún es tragedia, al menos en su forma. Analizar técnicamente las últimas piezas de este dramaturgo es comprender que la tragedia es a finales del s. V a.C. también -y, quizás, sobre todo- ejercicio literario ${ }^{54}$.

\section{BIBLIOGRAFÍA}

BARner, W. (1971), «Die Monodie» en W. Jens (ed.), Die Bauformen der griechischen Tragödie, München: 277-320.

BienL, W. (1968), «Zur Darstellung des Menschen in Euripides' Orestes», Helikon 8: 197-221. BurnetT, A.P. (1971), Catastrophe Survived. Euripides' Plays of mixed Reversal. Oxford.

Chantraine, P. (1968), Dictionnaire étymologigue de la langue grecque. Histoire des mots. Paris.

Conacher, D.J. (1967), Euripidean Drama. Myth, Theme and Structure. Toronto.

Damen, M. (1990), «Electra's Monody and the Role of the Chorus in Euripides' Orestes 9601012», TAPhA 120: 133-145.

Encinas Reguero, M.C. (2010), «Die Darstellung der Sieben in Euripides’ Phönissen. Der Fall des Kapaneus», WJA: (en prensa).

Euben, J.P. (1986), «Political Corruption in Euripides' Orestes» en J.P. Euben (ed.), Greek Tragedy and Political Theory, Berkeley-Los Angeles-London: 222-251.

Fraenkel, E. (1950), Aeschylus. Agamemnon, Vol. III. Oxford.

- (1964), «Die Kassandraszene der Orestie», Kleine Beiträge zur klassischen Philologie, Erster Band, Rome: 375-387.

Fuqua, C. (1976), «Studies in the Use of Myth in Sophocles' Philoctetes and the Orestes of Euripides», Traditio 32: 29-95.

GreenBERG, N.A. (1962), «Euripides' Orestes: an Interpretation», HSCP 66: 157-192.

Hall, E. (1993), «Political and Cosmic Turbulence in Euripides' Orestes» en A.H. Sommerstein, S. Halliwell, J. Henderson, B. Zimmermann (eds.), Tragedy, Comedy and the Polis. Papers from the Greek Drama Conference (Nottingham, 18-20 July 1990), Bari: 263-285.

Hose, M. (1994), «Der 'unnötig schlechte Charakter'. Bemerkungen zu Aristoteles' Poetik und Euripides' Orestes», Poetica 26: 233-255.

- (2008), Euripides. Der Dichter der Leidenschaften. München.

IRIARTE, A. (1996), «Casandra trágica», Enrahonar 26: 65-80.

Jong, I.J.F. de (1991), Narrative in Drama. The Art of the Euripidean Messenger-Speech. Leiden. Knox, B. (1979), Word and Action. Essays on the Ancient Theater. Baltimore-London.

LeAHY, D.M. (1969), «The Rôle of Cassandra in the Oresteia of Aeschylus», BRL 52: 144-177.

${ }^{54}$ Como Quijada (2002: 90) pone de relieve, algunas características de Orestes «ponen en evidencia un estadio final en la evolución del género, que se siente auto-contemplativo de la propia tradición en la que vive, y que da muestras de haberse convertido, de teatro de la polis, en mera literatura». 
McClure, L. (1999), Spoken like a Woman. Speech and Gender in Athenian Drama. New Jersey.

Mitchell-Boyask, R. (2006), «The Marriage of Cassandra and the Oresteia: Text, Image, Performance», TAPA 136: 269-297.

Montiglio, S. (2000), Silence in the Land of Logos. Princeton.

Mullens, H.G. (1940), «The Meaning of Euripides' Orestes», CQ 34: 153-158.

Porter, J.R. (1994), Studies in Euripides'Orestes. Leiden-New York-Köln.

QuiJADA, M. (1991), La composición de la tragedia tardía de Eurípides. Ifigenia entre los Tauros, Helena y Orestes. Vitoria.

- (2002), «Virtuosismo e innovación en la monodia trágica, Eurípides, Or. 1369-1502» en M.J. García Soler (ed.), TIMHг XAPIN. Homenaje al Profesor Pedro A. Gainzarain, Vitoria: 89-97.

Reinhardt, K. (1949), Aischylos als Regisseur und Theologe. Bern.

SCARCELlA, A.M. (1956), «Letture euripidee: l' Orestes e il problema dell'unità», Dioniso 19: 266-276.

Schein, S.L (1982), «The Cassandra Scene in Aeschylus’ Agamemnon», G\&R 29: 11-16.

Vellacott, P. (1975), Ironic Drama. A Study of Euripides'Method and Meaning. Cambridge.

Whallon, W. (1980), Problem and Spectacle. Studies in the Oresteia. Heidelberg.

Wolff, C. (1983), «Orestes» en E. Segal (ed.), Greek Tragedy. Modern Essays in Criticism, New York: 340-356.

Wright, M. (2006), «Orestes, a Euripidean Sequel», CQ 56: 33-47.

Yates, M.D. (1995), The Son of the Serpent: the Orestes-Figure in the Tragedies of Euripides. Ann Arbor (Diss. California 1993).

Zeitlin, F.I. (1980), «The Closet of Masks: Role-Playing and Myth-Making in the Orestes of Euripides», Ramus 9: 51-77. 